\title{
Chapter 19 \\ Natural Diversity: How Taking the Bio- out of Biodiversity Aligns with Conservation Priorities
}

\author{
Carlos Santana
}

\begin{abstract}
The concept of biodiversity, I argue, is poorly suited as an indicator of conservation value. An earlier concept, natural diversity, fits the role better. Natural diversity is broader than biodiversity not only in moving beyond taxonomic categories to encompass other patterns in the tapestry of life, but also in including abiotic, but valuable, aspects of nature. It encompasses, for instance, geological curiosities, natural entities of historical and cultural significance, and parts of nature with unique recreational and aesthetic value. It allows us to capture the idea of a diversity of ecosystem services, many of which are abiotic or have significant abiotic components. I make the case that refocusing conservation science around natural diversity retains many of benefits of using biodiversity as an indicator of value, while avoiding many of biodiversity's shortcomings. In particular, it provides a framework that highlights the conservation value of many biodiversity "coldspots," avoids the injustice of making conservation primarily the responsibility of the global south/developing world, and fits more neatly with the legal and ethical frameworks used to make conservation decisions in the public sphere.
\end{abstract}

Keywords Biodiversity $\cdot$ Ecosystem services $\cdot$ Environmental science

Summers in the Great Basin Desert of the Western United States are often intolerably hot and dry, but this is mitigated by the fact that in the Great Basin you're never far from a mountain range. One hot summer a decade or so ago, some friends and I escaped the heat by hiking up Mount Timpanogos, home of the only glacier in Utah. A highlight of the trek was taking a shortcut on the descent by sliding down the glacier. Years later I recounted this to a colleague who moved to Utah more recently,

C. Santana $(\bowtie)$

University of Utah, Salt Lake City, UT, USA

e-mail: c.santana@utah.edu

E. Casetta et al. (eds.), From Assessing to Conserving Biodiversity, 
and she replied, "what glacier?" A quick online search revealed that the glacier has retreated to below the talus and hikers can no longer slide down it, one of many signs that our Great Basin environment is being reshaped by climate change.

Glaciers won't be the only climate losers in Utah. Decades earlier, famed environmentalist and author Edward Abbey wrote about ascending Tukuhnikivats, a mountain near Arches National Monument. He calls the mountain an "island in the desert" and flees to it in the heat of late August (Abbey 2011: 217). Scrambling up the talus below the summit late in his hike, he hears the whistles of pikas, a sound he equates with the experience of reaching the summit (ibid: 224). Pikas are rabbitlike creatures which in Utah live only in alpine and subalpine zones. For the pika, the mountain peaks are quite literally islands in the desert, and as the Earth warms and the tree line creeps upward, those islands will become submerged. Soon there may be no more pikas in Utah, and none of us will be able to relive Abbey's famous experience.

These losses due to climate change are obviously losses of some sort of value. I want to probe how we conceptualize that loss of value. In the case of the pika, one ready answer is that if the pika goes locally extinct, we will have lost biodiversity (in the form of species richness). That biodiversity loss encompasses and explains the various ways in which losing the pika is a loss of value, including the inability to relive Abbey's hike the way he experienced it. But what about the glacier which I slid down as a young man? Its loss is also a loss of value, and it's a shame that my present-day students can't recreate the experience I had when I hiked Timpanogos. The loss of the glacier is not a biodiversity loss, but it feels like a loss of much the same sort as the loss of the pika. This similarity suggests a need for a concept that encompasses both sorts of loss.

Moreover, we need a concept that better captures the way in which having alpine islands in the desert is valuable. It isn't merely the way the pikas and the alpine flora contribute to local biodiversity. By providing a contrast to the desert valleys belowin biodiversity, yes, but also in aesthetic experience, in ecosystem services provided, and even in temperature and humidity - the mountain peaks contribute to Utah's natural diversity. The loss of our last glacier is a loss of natural diversity, even if it isn't a loss in biodiversity, ${ }^{1}$ and that same feature will be true of all sorts of changes in ecological value.

Biodiversity plays a central role in how we measure and discuss value in the conservation context, but it is an inadequate indicator of ecological value. The more inclusive concept of natural diversity avoids most of these shortcomings without bringing significant new baggage of its own. These reasons, I suggest, warrant placing natural diversity in the central conservation role that biodiversity currently occupies. At the very least, entertaining the concept of natural diversity can, by providing

\footnotetext{
${ }^{1}$ It is probable, of course, that the glacier contributes to the diversity of the microbiome. Suppose, however, that the microbial diversity persists under the talus but the glacier remains inaccessible to hikers. This is still a loss of value. Furthermore, even if some microbial diversity is lost, it is implausible that most of the loss of value is explained by the loss of the microbial diversity.
} 
a useful contrast, clarify many of the issues in assessing and characterizing biodiversity that motivate this volume.

\subsection{The Shortcomings of Biodiversity}

Biodiversity occupies a central place in conservation science as an object of measurement, a basis for decisions in conservation planning, and as the primary conservation objective. ${ }^{2}$ In occupying these roles, biodiversity is an organizing concept which focuses and unifies conservation research, and an umbrella concept (Lévêque 1994) which covers a broad array of conservation concerns. By playing this key role biodiversity serves as a representative of ecological value, the complete set of environmental goods of any sort - not only the intrinsic value of natural entities, but the economic, aesthetic, cultural, recreational, spiritual, and health amenities they provide (Santana 2016). Ecological value in this broad sense is the grounds for conservation efforts, so as Norton argues, the right definition of biodiversity is one "rich enough to capture all that we mean by, and value in, nature" (2006: 57). By conserving biodiversity, we aim to conserve ecological value of all kinds. In many ways biodiversity is well suited to this task. Ecological value of most kinds tends to depend on the living organisms that compose ecosystems, and thus on biodiversity. Conversely, since biodiversity relies on many ecological factors, including abiotic processes (Noss 1990), biodiversity conservation entails the conservation of other natural goods. Biodiversity can be operationalized in various useful ways, such as counts of richness (number of units), relative abundance, and measures of difference. It can also be assessed at biological levels of various sorts, such as genes, species, and ecosystems. This makes for flexible, scientifically meaningful, and computationally tractable measures that can feed into conservation planning (Sarkar and Margules 2002). Biodiversity also has an inclusive scope, allowing us to argue for the conservation of species and populations which might fall through the cracks were we to prioritize a different indicator of ecological value. For all these reasons, biodiversity makes sense as a conservation target.

The concept of biodiversity has come under scrutiny, however, in large part because of a sizeable gap between biodiversity value and ecological value construed broadly. It's easy, as a working conservationist, to lose sight of the connection between what's being measured and ecological value. For this reason, even some defenders of biodiversity worry, writing "we do not think that measurement strategies in conservation biology have been convincingly connected to wider theories that show the importance of the magnitudes measured" (Maclaurin and Sterelny 2008: 149). The assumption that our measurements of genes, species, higher taxa

\footnotetext{
${ }^{2}$ Biological diversity also plays important roles outside the context of conservation, such as an explanandum in ecology and evolutionary biology. This chapter isn't concerned with these roles, but more narrowly with biodiversity's central role in conservation.
} 
and so on adequately represent those economic, cultural, aesthetic, and other values needs to be called into question.

Many researchers have done just that, calling into question how our measures of biodiversity relate to ecological value. Sarkar (2002; see also his 2008 and 2016), for instance, notes that the standard units of diversity in conservation biology fail to capture important units of ecological value, such as butterfly migration patterns. He argues that we should adopt a highly-flexible, open-ended concept of biodiversity. On Sarkar's picture, selecting the object of measurement (the true surrogate) when we assess biodiversity "is not an empirical question; rather it must be settled by convention" (2014: 5). Specifically, each local, conventional definition of biodiversity should be "based on normative considerations" that reflect the individual context and local cultural values (2014: 5-6). In this way, biodiversity measures can be tailored to account for, say, the cultural significance of a non-endangered species such as the Bald Eagle, which was never in danger of extinction but merited costly conservation efforts (2014). In its most extreme form, this deflationary, contextual account of biodiversity would give up on the content of the concept of biodiversity (i.e. that it is about the biota and about diversity) to allow it to encompass the whole range of ecological values. Sarkar's more recent work $(2014,2016)$ disavows this extreme stance, but the issues which motivated a more deflationary account of biodiversity remain.

Alternatively, Maier (2012) argues in detail that extant defenses of the value of biodiversity all commit fallacies, perhaps most significantly that of conflating the value of biodiversity with the value of other individual entities such as species and ecosystem processes. It is these natural entities that have value, and not the systemlevel property of being biodiverse. Motivated by similar issues, Santana (2014, 2016) argues that biodiversity is often a poor indicator of others sorts of ecological value. For example, cultural and aesthetic values often attach to places existing in a preferred state, even if that state has lower biodiversity than a possible alternative. Invasive plant species, for instance, can sometimes coexist alongside indigenous plants, meaning that invasions can increase biodiversity (Cleland et al. 2004). But we are still justified, because of our attachment to historical landscapes, in fighting benignly invasive species. To give another example, the units of biodiversity (species, phyla, genes, etc.) are, in measurement practice, interchangeable with other units of the same type. Consequently, biodiversity measures ignore the way in which some units differ significantly in value from others. They ignore, for instance, how a bat species which eats tons of disease-carrying mosquitos has higher ecological value than the mosquito species it eats. ${ }^{3}$ Another set of critics, Morar et al., put the

\footnotetext{
${ }^{3}$ True, biodiversity measures can be sensitive to where organisms sit in the trophic network, not only through direct measures of trophic diversity, but also because the secondary effects of biodiversity loss are mediated by the structure of the trophic network (Dunne et al. 2002), and because trophic factors may regulate levels of species diversity (Terborgh 2015).

But my claim here isn't that biodiversity measures are insensitive to the importance of trophic roles to ecosystem function. I'm claiming that important normative considerations (e.g. malaria is value-negative) are largely invisible to biodiversity measures. Because malaria is value-negative, mosquito species which transmit malaria have less value, and bat species which prey on those
} 
issue succinctly: "there are good reasons to doubt whether [biodiversity] provides any guidance for environmental decision-makers or has any clearly established relationship with those aspects of nature about which we care the most" (2015: 16-17).

In addition to worries about the gap between ecological value and biodiversity measures, Morar et al. accuse the concept of biodiversity as presenting a veneer of scientific objectivity while conservation scientists undemocratically impose their own environmental values on policy-making. According to this argument, the normativity of the biodiversity concept means that the policies supported by the techniques of conservation biology are value-laden. Whose values? The scientists' values, since they choose how to define and measure biodiversity. But this isn't transparent to society at large, thus the values of the broader public might not have an appropriate input to conservation decision-making. The focus on biodiversity conservation is, in effect, an injustice through technocracy. For this reason, Kareiva and Marvier (2012) suggest that conservation biology reframe itself as an interdisciplinary conservation science, one which uses social science to better measure anthropocentric ecological value. The original sin of conservation biology, they argue, was its "inattention to human well-being" (2012: 963). If biodiversity is at the heart of what matters, then "the vast majority of people are a threat" to ecological value, rather than among its beneficiaries (ibid). The focus on biodiversity conservation has thus unjustly relegated socially-oriented ecological values to the background.

Mismatch between biodiversity value and ecological value shows up in practice as well as theory, perhaps most notably in how biodiversity conservation is largely a burden on the "Global South." Although conservation biology emerged in wealthy industrialized countries (the "Global North"), biodiversity increases on a latitudinal gradient that peaks at the equator (Hillebrand 2004), meaning that most biodiversity is concentrated in the less-developed tropical and subtropical nations of the Global South. Likewise, the areas identified by conservation biologists as biodiversity hotspots - the places of highest conservation concern-are mostly in South America, Africa, South Asia, and tropical islands (Myers et al. 2000). We hear a lot about saving the rainforests and coral reefs, but not so much about how the American Midwest is no longer a place where "the buffalo roam and the deer and the antelope play," in the words of a nineteenth century folk song. As a result, conservation has focused much more on the Global South, and while biodiversity conservation and economic development are not always in competition (Tallis et al. 2008), there are almost always tradeoffs (McShane et al. 2011). Most importantly, a chief tool of conservation biology is setting aside protected areas (Rands et al. 2010; Miller et al. 2011), which often imposes significant burdens on local people and indigenous groups (Adams et al. 2004). For this reason, socially-oriented environmental researchers have often been at odds with conservation biologists and environmental philosophers who extoll biodiversity value (Miller et al. 2011). The focus on biodi-

mosquitos are more valuable. Bats and mosquitos thus exhibit a value differential, one that is explained by factors independent of their relative contributions to biodiversity, and so isn't easy represented by a biodiversity measure. 
versity conservation has thus been a double injustice, placing unfair burdens on the Global South, and ignoring ecological values in the Global North and biodiversity "cold-spots" more generally.

\subsection{Natural Diversity as an Alternative}

Deconstruct biodiversity into its two components, biological and diversity. My proposal is that the chief virtues of treating biodiversity as the primary target of conservation come solely from the diversity component. Conversely most of the problematic features of biodiversity arise from the biological component, since it is the focus on organisms which excludes many sources of value. We should therefore aim to retain the benefits of the diversity component while mitigating the drawbacks of the biological component.

A good candidate for doing so would be to supplant the concept of biodiversity in conservation concepts with a diversity concept that extends beyond the biological, which I'll call natural diversity. The United Nations Convention on Biological Diversity defines biodiversity as "the variability among living organisms from all sources 4 ;" modeled on that definition, we can define natural diversity as 'the variability among natural entities from all sources'. Note that this is a departure from some previous usage of the term, which has sometimes equated natural diversity with what we would now call biodiversity (e.g. in Terborgh 1974, or as used in U.S. Fish \& Wildlife Service directive $701 \mathrm{FW} 1$ ). In the broader sense of natural diversity that I have specified, preserving natural diversity is a better conservation goal than preserving biodiversity because it retains the benefits of the diversity component, but moves beyond the biological component.

The chief virtues of biodiversity as an organizing concept in conservation are its flexibility and its inclusivity. What makes biodiversity so flexible is the number of ways we can operationalize it: as species richness, as complementarity, as functional diversity, and so on. As a broader concept, natural diversity could be operationalized even more flexibly, for instance in measures of abiotic soil components, as diversity of human experience of landscapes (measured through psychological or economic methods), or as measures of geological composition, ${ }^{5}$ to give a few examples. Measures such as these might account for how the loss of a glacier is a loss of ecological value even if there is no corresponding loss of biodiversity. Natural diversity would thus be a more flexible conservation target.

It would also be more inclusive, for similar reasons. Natural diversity includes the diversity of living things, but also other forms of diversity. Lakes whose mineral

\footnotetext{
${ }^{4}$ https://www.cbd.int/convention/articles/default.shtml?a=cbd-02

${ }^{5}$ This might draw on extant conceptions of geodiversity (Kozłowski 2004; Gray 2004), or some alternative. Either way, because natural diversity includes cultural, historical, economic, and experiential components (among other things), it is more than just biodiversity supplemented with geodiversity.
} 
content is too high to support the diversity of species other lakes support (e.g. Mono Lake or the Great Salt Lake) still contribute to natural diversity, partially in virtue of being inhospitable to most forms of biodiversity! ${ }^{6}$ A barren sandstone cliff which hosts few organisms, and thus contributes little to biodiversity, might support unique climbing routes and thus have high ecological value. The frigid Kola Peninsula in the Russian Arctic won't show up on any maps of biodiversity hotspots, but its unusual mineral assemblages are of great scientific interest. An area held to be uniquely sacred by an indigenous group is naturally diverse for that reason, even if it isn't biodiverse. A waterway which hosts no endangered species may provide a unique transportation corridor for the local population. If our aim is to conserve natural diversity, all these places will rank high in ecological value, but if biodiversity is our primary conservation goal, they might be ignored. Natural diversity is thus a more inclusive concept than biodiversity.

In addition to surpassing biodiversity in the virtues of flexibility and inclusiveness, natural diversity avoids some (but not all) of biodiversity's vices. Most importantly, as the examples in the last paragraph highlight, it is a better indicator of ecological value. Any natural entity of distinctive ecological value is a significant site of natural diversity in virtue of that distinctiveness. This includes entities of distinctive cultural, recreational, scientific, and economic value, even if those entities contribute little to biodiversity. The gap between natural diversity and ecological value is thus much smaller than the gap between biodiversity and ecological value. Some gap will remain, since some ecological value just doesn't fall under the rubric of diversity in any form, as Maier (2012) and Santana (2016) demonstrate. No single concept that is anything less than intolerably vague is likely to encompass everything of ecological value, however, and that natural diversity does better than biodiversity is a strong point in its favor.

Natural diversity also avoids the potentially unjust ramifications of using biodiversity as the central conservation concept. We have no reason to expect that natural diversity hotspots will cluster in the Global South or that any components of natural diversity besides biodiversity increase on a latitudinal gradient. If natural diversity is the more fundamental concept, conservationists should take the loss of visible stars in a European city to be a loss of conservation value commensurable with (though not necessarily equal to) the loss of an insect species in Madagascar. Consider the following contrast: the rowdy Canadian filmmakers who needlessly damaged unusual natural wonders in the U.S., such as the Bonneville Salt Flats and Yellowstone's Grand Prismatic Spring, got off with a small fine and are publicly called "good young men" (Penrod 2016). In South Africa, by contrast, impoverished hunters who kill endangered species are themselves killed by the hundreds and imprisoned by the thousands (Burleigh 2017). Although damaging a tract of salt flat may not be as morally significant as killing a sentient animal, there is clearly something inequitable in how those who harm natural diversity in the developed

\footnotetext{
${ }^{6}$ Uniquely inhospitable environments host unique organisms such as extremophiles, and so contribute to biodiversity as well, but (a) still have comparatively low biodiversity, and (b) their biodiversity value is the lesser part of their value.
} 
world receive a mere slap on the wrist, while those who harm biodiversity in the developing world can pay with their lives. In terms of conservation value, both cases are serious losses of natural diversity and we should expend commensurate efforts to promote conservation in both cases. In fact, given that individual rhinos and elephants are more easily replaced than individual geological oddities, in terms of conservation values ${ }^{7}$ the "good young men" may have caused more harm than any individual poacher. Obviously, few conservationists would endorse the murder of South African poachers. But a biodiversity-centered conservation framework does entail that the actions of the poachers are much more serious than the actions of the thoughtless filmmakers. A natural diversity framework, on the other hand, entails that the actions of both poacher and "good young man" are of a type: harm to natural diversity. The threats to natural diversity, like natural diversity itself, are thus globally distributed, and the burdens of conservation are correspondingly placed as much on the shoulders of relatively wealthy First-Worlders as much as they are on the backs of the Global South.

Another advantage of natural diversity as the central value concept in justifying protected areas is that legal frameworks for establishing conservation areas already appeal to something like it. At the very least, the law typically subordinates biodiversity to a broader class of values. In one chapter of her book Imagining Extinction, Heise examines how conservation law around the world is not preoccupied with "mainly a matter of counting how many species have been preserved or have died out," but more with fulfilling "the political, social, and cultural purposes to which it links the conservation of biodiversity" (2016: 91-92). For example, German law "protects endangered species for the sake of conserving culturally defined landscapes rather than habitats for the sake of species" (2016: 90). In other words, the law prioritizes a set of landscapes, which is diversity at the level of natural diversity, not biodiversity. In Bolivia, as Heise recounts, biodiversity conservation is legally situated as part of laws situating the Earth itself as a legal subject, and which invoke the cosmologies of indigenous people (2016: 114-116). Biodiversity conservation's ultimate justification in such a system is thus its contribution to a broader category, "the differentiation and variety of the beings that make Mother Earth" (2016: 116), which sounds more like natural diversity. Even in the United States, where the Endangered Species Act is so central to the environmentalist's toolkit, much, perhaps most, of the legal justification for setting aside protected areas comes from the American Antiquities Act of 1906 (Harmon et al. 2006), which justifies protection not of biodiversity, but of "objects of historic or scientific interest." These sorts of objects are cultural, archaeological, and geological features which may not fall under the rubric of biodiversity, but do contribute to natural diversity more broadly. Furthermore, the designation of national and state parks, which are some of the

\footnotetext{
${ }^{7}$ There are non-conservation values at play here as well: large mammals are sentient, and thus hedonistic values matter as well. But poaching is a bad mostly in terms of conservation value-if the suffering inflicted on the hunted animals was the chief concern, poaching would be no worse than the hunting of unprotected species, and much less immoral than eating factory-farmed meat. For present purposes, we thus have no grounds to say that the reckless filmmakers' crime, because they made no living thing suffer, was less serious than poaching.
} 
most significant protected areas, is justified by the unique aesthetic and recreational opportunities they provide more than the species they protect. Across much of the globe, natural diversity better captures the systems of value behind the legal justifications for conservation, much of which either does not invoke biodiversity or places the value of biodiversity subordinate to a broader class of natural values.

The impulse to protect biodiversity is plausibly grounded in a reasonable aversion towards losing unique, rare, unusual, and distinctive parts of our world. In other words, we find real value in diversity. But this is true not just of biological organisms, but of unique, rare, unusual, and distinctive natural goods of all sorts-of natural diversity inclusive of, but going beyond, biodiversity. An ethnic group's ancestral homeland is unique in virtue of that fact, and merits preservation because in its uniqueness it represents natural diversity. A landscape that is a local rarity, like a glacier in Utah, is particularly valuable in virtue of that rarity. An unusual environment, such as undersea thermal vents, is scientifically valuable in part because it is unusual in abiotic as well as biotic composition. These sorts of natural values fall clearly under a notion of diversity, but not under biological diversity. The concept of natural diversity thus retains the conceptual benefits of biodiversity, while better fulfilling the role of capturing value in the natural world. Moreover, the political implications of conserving natural diversity are both more commonsensical and less unjust than a focus on conserving biodiversity primarily. Insofar as they are concepts competing for the same conceptual role, natural diversity thus has a clear advantage.

\subsection{Operationalizability}

Let's consider a possible disadvantage of natural diversity. Biodiversity serves not only as an indicator of ecological value, but as a measurement concept. Conservationists can operationalize biodiversity in various ways, estimate the amount of biodiversity in different areas, and use these estimates as inputs to conservation decision-making. Natural diversity, as a broader, less cohesive concept, might be more resistant to operationalization, and thus less useful as a measurement concept.

I don't think this is the case, in large part because biodiversity is itself extremely resistant to operationalization and measurement. Natural diversity comes down to meaning something close to "all of nature," and it seems almost nonsensical to try to argue that some areas have more nature than others. But as Sarkar insightfully points out, standard definitions of biodiversity equate it to "all of biology" (2002: 137) as well. ${ }^{8}$ Morar et al. contend, with supporting citations to a dozen or so

\footnotetext{
${ }^{8}$ Many writers have observed that the term biodiversity is even more vague than "all of biology." Blandin suggests that biodiversity is just a new incarnation of nature, and has become "aussi indéfinissable que l'est la nature [as indefinable as nature]" (2014:51). Similarly, others have suggested that biodiversity is interpreted flexibly, with each interpreter using the vagueness of the term to
} 
conservation biologists and philosophers, that "the widest consensus about biodiversity understood in this broad and all-inclusive sense is that it cannot, as a matter of principle, be quantified, due to its multidimensionality and the lack of commensurability and covariance among its components" (2015: 18). True, biodiversity can be made amenable to precise measurement, but only by ignoring most its components to focus on merely one or two at a time, such as species richness, genes, traits, habitat types and so on. But this gives biodiversity no advantage over natural diversity. While natural diversity, broadly construed, is utterly unquantifiable, there is nothing preventing picking a couple of dimensions at a time for particular purposes and measuring those. We could, for instance, in selecting conservation areas have measures of recreational usage, number of archaeological sites, and biological family richness, and use all three in tandem to determine what areas to prioritize. This leaves out much of natural diversity, but any practical measure of biodiversity is similarly limited. So, the breadth and vagueness of natural diversity is no different in kind than that of biodiversity.

We might worry, however, that the great flexibility available in selecting indicators of natural diversity will lead to inconsistent measures of natural diversity. Again, on this score natural diversity does no worse than biodiversity. With biodiversity measures, "there will always be some way of comparing (say) one wetland to another that will count the first as the more diverse, and another procedure that will reverse the result" (Maclaurin and Sterelny 2008: 133). This inconsistency across different methods of measurement may be a feature and not a bug, however. Sarkar $(2002,2008)$ argues that the ability to have different measures of biodiversity which yield different results allows us to fit our concept of biodiversity to the conservation priorities of each local situation, which differ from context to context. If this situational flexibility is a beneficial feature of biodiversity measures, then it would also be a feature of natural diversity measures. The difference, of course, would be even greater flexibility with natural diversity, and a greater ability to use measures which closely track non-biotic entities of ecological value. What might have seemed to be an objection to natural diversity - the sheer range of specific ways to quantify it-turns out to be a point in its favor.

read into whatever it is they value in nature. Takacs, for instance writes that "[i]n biodiversity, each of us finds a mirror for our most treasured natural images, our most fervent environmental concerns" (1996:81; cited in Morar et al. 2015). And Blondel observes that biodiversity is "coquille vide ou chacun met ce qu'il veut [an empty shell in which each person places whatever they want to see]" (1995: 225). (Thanks to Elena Casetta for help with the French references and translations). 


\subsection{More Than Ecosystem Diversity}

The astute reader might be wondering whether the concept of natural diversity treads new ground. Doesn't ecosystem diversity, for instance, already cover the same territory? Ecosystem diversity is often treated as the one of the three main components of biodiversity, with species and genetic diversity being the others (McNeely et al. 1990). As the diversity of habitat types and community structure and composition (Sohier 2007), it seems that ecosystem diversity captures many of the abiotic entities and landscape-level features that I have argued require a move from bio- to natural diversity. I grant that, when taken seriously as a component of biodiversity, ecosystem diversity addresses some of the worries I have raised. But not most of them, since it only values abiotic entities and landscape features qua contributors to biotic activity, and not in terms of many other facets of ecological value, such as aesthetic or economic contributions. For this reason, I think ecosystem diversity still falls short.

\subsection{A Natural Bridge}

The concept of biodiversity, as I've discussed, has come under attack from several fronts. One reaction to these attacks could be to abandon it and move to some other means of representing and measuring ecological value. Leading alternatives are found in the social sciences, particularly economics, and focus on non-market valuation methods. ${ }^{9}$ To abandon biodiversity for economic demand values would likely be to push the non-human biota too far into the background. It would also require us to give up much of the valuable research that conservation biologists have conducted, and leave behind useful tools they have developed. In addition, we would be abandoning a concept that has gained political and rhetorical importance. All these considerations imply that the cost of biodiversity eliminativism is very high.

Natural diversity, I am proposing, is a way to move beyond biodiversity in a way that avoids paying much of this cost. Natural diversity can be a bridge between traditional biodiversity-focused conservation and socially-focused environmental planning, because it includes both biodiversity and human-generated values under an umbrella concept. It suggests that, in principle, various sorts of ecological value are commensurable, and thus we can take research on biodiversity conservation and put it in conversation with other conservation strategies and goals. Of course, the extant concept ecosystem services (Millenium Ecosystem Assessment 2005) already tries to do this. Biodiversity and ecosystem services, however, are often an awkward fit. One way to include biodiversity in the ecosystem services framework is to just include biodiversity as a final ecosystem service (Mace et al. 2012). But this is ad

\footnotetext{
${ }^{9}$ For an introduction to these methods of environmental valuation, see Champ et al. (2003).
} 
hoc, and doesn't really suggest in what way biodiversity is comparable to other services. In practice, this often means that valuations of ecosystem services, which are most easily quantified in economic terms, will rate the value of biodiversity quite low (Fromm 2000; Heinzerling 2016). Another means of trying to incorporate biodiversity in the ecosystem services approach is to argue that other services are reliant on biodiversity, but the relationship between biodiversity and ecosystem services is anything but straightforward (Srivastava and Vellend 2005; Mace et al. 2012). What natural diversity offers is an alternative, perhaps superior, means of accomplishing the same goal. Shoehorning biodiversity into the ecosystem services approach falls short because it is ad hoc and has no common standard of comparison. But a natural diversity approach would take the extant tools of biodiversity conservation planning and apply them to a broader set of ecological values, in a natural extension of existing conservation biology. In pitching natural diversity, I'm attempting to refocus our conservation thinking on those glaciers, and landscapes, and ancestral homelands, and other natural features that fall out of the conversation when we discuss biodiversity. But I'm raising the possibility of doing so in a way that is an organic expansion of biodiversity thinking and extant conservation practice, rather than leaving it behind as we embrace a broader set of ecological values.

\section{References}

Abbey, E. (2011). Desert solitaire: A season in the wilderness. Retrieved from http://ebookcentral. proquest.com

Adams, W. M., Aveling, R., Brockington, D., Dickson, B., Elliott, J., Hutton, J., et al. (2004). Biodiversity conservation and the eradication of poverty. Science, 306(5699), 1146-1149.

Blandin, P. (2014). « La diversité du vivant avant (et après) la biodiversité: repères historiques et épistémologiques ». In E. Casetta \& J. Delord (Eds.), La biodiversité en question. Enjeux philosophiques, éthiques et scientifiques, Les Éditions Materiologiques (pp. 31-68).

Blondel J. (1995). Biogéographie. Approche écologique et évolutive, Masson

Burleigh, N. (2017, August 8). Kruger Park South Africa: Where black poachers are hunted as much as their prey. Newsweek. http://www.newsweek.com/2017/08/18/trophy-hunting-poachers-rhinos-south-africa-647410.html

Champ, P. A., Boyle, K. J., \& Brown, T. C. (Eds.). (2003). A primer on non- market valuation. Boston, MA: Kluwer Academic Publishers.

Cleland, E. E., Smith, M. D., Andelman, S. J., Bowles, C., Carney, K. M., Claire Horner-Devine, M., ... \& Vandermast, D. B. (2004). Invasion in space and time: Non-native species richness and relative abundance respond to interannual variation in productivity and diversity. Ecology Letters, 7(10), 947-957.

Dunne, J. A., Williams, R. J., \& Martinez, N. D. (2002). Network structure and biodiversity loss in food webs: Robustness increases with connectance. Ecology Letters, 5(4), 558-567.

Fromm, O. (2000). Ecological structure and functions of biodiversity as elements of its total economic value. Environmental and Resource Economics, 16(3), 303-328.

Gray, M. (2004). Geodiversity: Valuing and conserving abiotic nature. Chichester: Wiley. 
Harmon, D., McManamon, F. P., \& Pitcaithley, D. T. (2006, January). The antiquities act: The first hundred years of a landmark law. The George Wright Forum, 23(1), 5-27. George Wright Society.

Heinzerling, L. (2016). Economizing on nature's bounty. In J. Garson, A. Plutynski, \& S. Sarkar (Eds.), The Routledge handbook of philosophy of biodiversity. London: Taylor \& Francis.

Heise, U. K. (2016). Imagining extinction: The cultural meanings of endangered species. Chicago: University of Chicago Press.

Hillebrand, H. (2004). On the generality of the latitudinal diversity gradient. The American Naturalist, 163(2), 192-211.

Kareiva, P., \& Marvier, M. (2012). What is conservation science? BioScience, 62(11), 962-969.

Kozłowski, S. (2004). Geodiversity. The concept and scope of geodiversity. Przeglad Geologiczny, $52(8 / 2), 833-883$.

Lévêque, C. (1994). Le concept de biodiversité: de nouveaux regards sur la nature. Natures Sciences Sociétés, 2(3), 243-254.

Mace, G. M., Norris, K., \& Fitter, A. H. (2012). Biodiversity and ecosystem services: A multilayered relationship. Trends in Ecology \& Evolution, 27(1), 19-26.

Maclaurin, J., \& Sterelny, K. (2008). What is biodiversity? Chicago: University of Chicago Press.

Maier, D. S. (2012). What's so good about biodiversity?: A call for better reasoning about nature's value (Vol. 19). Dordrecht: Springer.

McNeely, J. A., Miller, K. R., Reid, W. V., Mittermeier, R. A., \& Werner, T. B. (1990). Conserving the world's biological diversity. Washington, DC: IUCN, World Resources Institute, Conservation International, WWFUS and the World Bank.

McShane, T. O., Hirsch, P. D., Trung, T. C., Songorwa, A. N., Kinzig, A., Monteferri, B., et al. (2011). Hard choices: Making trade-offs between biodiversity conservation and human wellbeing. Biological Conservation, 144(3), 966-972.

Millennium ecosystem assessment. (2005). Ecosystems and human wellbeing: A framework for assessment. Washington, DC: Island Press.

Miller, T. R., Minteer, B. A., \& Malan, L. C. (2011). The new conservation debate: The view from practical ethics. Biological Conservation, 144(3), 948-957.

Morar, N., Toadvine, T., \& Bohannan, B. J. (2015). Biodiversity at twenty-five years: Revolution or red herring? Ethics, Policy \& Environment, 18(1), 16-29.

Myers, N., Mittermeier, R. A., Mittermeier, C. G., Da Fonseca, G. A., \& Kent, J. (2000). Biodiversity hotspots for conservation priorities. Nature, 403(6772), 853.

Norton, B. (2006). Toward a policy-relevant definition of biodiversity. In The endangered species act at thirty (Vol. 2, pp. 49-58).

Noss, R. F. (1990). Indicators for monitoring biodiversity: A hierarchical approach. Conservation Biology, 4(4), 355-364.

Penrod, E. (2016, November 4). Canadian will pay fine for wakeboarding on Utah's Bonneville salt flats. The Salt Lake tribune. http://archive.sltrib.com/article.php?id=4546578\&itype=CM SID

Rands, M. R., Adams, W. M., Bennun, L., Butchart, S. H., Clements, A., Coomes, D., et al. (2010). Biodiversity conservation: Challenges beyond 2010. Science, 329(5997), 1298-1303.

Santana, C. (2014). Save the planet: Eliminate biodiversity. Biology \& Philosophy, 29(6), 761-780.

Santana, C. (2016). Biodiversity eliminativism. In The Routledge handbook of philosophy of biodiversity (pp. 100-109).

Sarkar, S. (2002). Defining "biodiversity"; Assessing biodiversity. The Monist, 85(1), 131-155.

Sarkar, S. (2008). Norms and the conservation of biodiversity. Resonance: Journal of Science Education, (7), 13.

Sarkar, S. (2014). Biodiversity and systematic conservation planning for the twenty-first century: A philosophical perspective. Conservation Science, 2(1). 
Sarkar, S. (2016). Approaches to biodiversity. The Routledge handbook of philosophy of biodiversity.

Sarkar, S., \& Margules, C. (2002). Operationalizing biodiversity for conservation planning. Journal of Biosciences, 27(4), 299-308.

Sohier, C. (2007). Ecosystem diversity. Available from http://www.coastalwiki.org/wiki/ Ecosystem_diversity. Accessed on 12 Nov 2017.

Srivastava, D. S., \& Vellend, M. (2005). Biodiversity-ecosystem function research: Is it relevant to conservation? Annual Review of Ecology Evolution and Systematics, 36, 267-294.

Takacs, D. (1996). The idea of biodiversity. Philosophies of paradise. Baltimore: Johns Hopkins University Press.

Tallis, H., Kareiva, P., Marvier, M., \& Chang, A. (2008). An ecosystem services framework to support both practical conservation and economic development. Proceedings of the National Academy of Sciences, 105(28), 9457-9464.

Terborgh, J. (1974). Preservation of natural diversity: The problem of extinction prone species. BioScience, 24(12), 715-722.

Terborgh, J. W. (2015). Toward a trophic theory of species diversity. Proceedings of the National Academy of Sciences, 112(37), 11415-11422.

Open Access This chapter is licensed under the terms of the Creative Commons Attribution 4.0 International License (http://creativecommons.org/licenses/by/4.0/), which permits use, sharing, adaptation, distribution and reproduction in any medium or format, as long as you give appropriate credit to the original author(s) and the source, provide a link to the Creative Commons licence and indicate if changes were made.

The images or other third party material in this chapter are included in the chapter's Creative Commons licence, unless indicated otherwise in a credit line to the material. If material is not included in the chapter's Creative Commons licence and your intended use is not permitted by statutory regulation or exceeds the permitted use, you will need to obtain permission directly from the copyright holder.

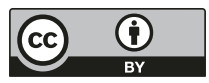

